\title{
Quiet time F2-layer disturbances: seasonal variations of the occurrence in the daytime sector
}

\author{
A. V. Mikhailov, A. H. Depueva, and V. H. Depuev \\ Institute of Terrestrial Magnetism, Ionosphere and Radio Wave Propagation, Troitsk, Moscow Region 142190, Russia
}

Received: 14 July 2008 - Revised: 23 October 2008 - Accepted: 30 October 2008 - Published: 21 January 2009

\begin{abstract}
Earlier revealed seasonal/latitudinal variations of the occurrence for positive and negative F2-layer Qdisturbances have been interpreted in the framework of the present-day concept of the thermosphere-ionosphere interaction. The basic process is the solar-driven and storminduced thermospheric circulation's interaction which varies with season and latitude. Such morphological features as clustering of negative Q-disturbances around winter solstice and the appearance of an additional occurrence of summer peak at lower latitudes, the equinoctial occurrence peaks for positive Q-disturbances and their merging to one summer peak at lower latitudes can be explained in the framework of this concept. Moreover, seasonal/latitudinal variations of the occurrence for usual storm-induced F2-layer disturbances, which exhibit quite different morphology, are also explained within this concept and this may be considered as its success. Although some types of F2-layer Q-disturbances are obviously related to the impact from below, the analyzed seasonal/latitudinal occurrence variations are shown to have their origin in the thermosphere itself.
\end{abstract}

Keywords. Atmospheric composition and structure (Thermosphere - composition and chemistry) - Ionosphere (Ionosphere-atmosphere interactions; Ionospheric disturbances)

\section{Introduction}

Quiet time F2-layer disturbances (Q-disturbances) are a weakly developed direction in the ionospheric physics. Both their morphology and formation mechanisms are different from the usual F2-layer storm effects related to geomagnetic activity (Mikhailov et al., 2004, 2007a, b). Q-disturbances at the geomagnetic equator also exhibit some peculiarities (Depueva et al., 2005; Depuev et al., 2008). At the beginning of our investigations we supposed that F2-layer Qdisturbances could be related to the impact from below - the so-called meteorological control of the Earth's ionosphere (e.g. Danilov, 1986; Danilov et al., 1987; Khachikjan, 1987; Kazimirovsky and Kokourov, 1991; Forbes et al., 2000; Rishbeth and Mendillo, 2001; Kazimirovsky et al., 2003; Laštovička et al., 2003; Vanina and Danilov, 2005). Quasi 2-day oscillations in the ionosphere (Chen, 1992; Apostolov et al., 1995; Forbes and Zhang, 1997; Forbes et al., 2000; Altadill and Apostolov, 2001; Rishbeth and Mendillo, 2001) have also been considered in relation to the Q-disturbances occurrence. Seismic events seem to also affect the F2-region (e.g. Hobara and Parrot, 2006; Sharma et al., 2006; Liu et al., 2006, and references therein). Although this impact from below is still considered as a candidate, at least, to explain some types of the F2-layer Q-disturbances and this is future work, our previous analysis has shown that the main morphological features can be explained in the framework of the contemporary understanding of the thermosphere-ionosphere interaction. That is, the sources of the considered Q-disturbances are located in the thermosphere itself.

It was shown (Mikhailov et al., 2007a, b) that negative and positive F2-layer Q-disturbances have different formation mechanisms and it would be interesting to use this understanding to explain seasonal variations of their occurrence. Therefore, the aim of the paper may be specified in the following way: to propose an explanation to the earlier revealed seasonal variations of the positive and negative Q-disturbances occurrence frequency at high, middle, and lower latitudes during daytime hours and to discuss the difference with usual storm-induced F2-layer disturbances.

\section{Correspondence to: A. V. Mikhailov} (avm71@orc.ru) 
Table 1. List of stations and periods of observations available, geodetic coordinates and invariant latitudes of the stations are given.

\begin{tabular}{lcccclcccc}
\hline Station & Lat & Lon & Inv. Lat & Years & Station & Lat & Lon & Inv. Lat & Years \\
\hline Kiruna & 67.8 & 20.4 & 64.4 & $57-99$ & Slough & 51.5 & -0.6 & 49.8 & $49-96$ \\
Sodankyla & 67.4 & 26.6 & 63.6 & $57-89$ & Dourbes & 50.1 & 4.6 & 47.8 & $57-90$ \\
Lycksele & 64.7 & 18.8 & 61.5 & $57-99$ & Kiev & 50.7 & 30.3 & 46.5 & $64-92$ \\
Arkhangelsk & 64.6 & 40.5 & 60.1 & $69-93$ & Irkutsk & 52.5 & 104.0 & 45.6 & $57-97$ \\
Uppsala & 59.8 & 17.6 & 56.6 & $57-99$ & Poitiers & 46.6 & 0.3 & 45.1 & $57-98$ \\
St. Petersburg & 59.9 & 30.7 & 55.9 & $57-98$ & Khabarovsk & 48.5 & 135.1 & 40.2 & $59-93$ \\
Magadan & 60.1 & 151.0 & 52.8 & $69-99$ & Sofia & 42.6 & 23.4 & 38.5 & $64-99$ \\
Juliusruh & 54.6 & 13.4 & 51.6 & $57-99$ & Rome & 41.9 & 12.5 & 37.2 & $58-98$ \\
Gorky & 56.1 & 44.3 & 51.4 & $58-89$ & Wakkanai & 45.4 & 141.7 & 36.7 & $57-90$ \\
Ekaterinburg & 56.7 & 61.1 & 51.4 & $57-95$ & Alma-Ata & 43.2 & 76.9 & 35.7 & $57-89$ \\
Kaliningrad & 54.7 & 20.6 & 51.2 & $64-94$ & Ashkhabad & 37.9 & 58.3 & 30.5 & $57-94$ \\
Tomsk & 56.5 & 84.9 & 50.9 & $57-97$ & Akita & 39.7 & 140.1 & 30.2 & $57-89$ \\
Moscow & 55.5 & 37.3 & 50.8 & $57-97$ & Kokubunji & 35.7 & 139.5 & 25.6 & $57-91$ \\
\hline
\end{tabular}

\section{Seasonal variations}

The morphology of the Q-disturbances occurrence was analyzed by Mikhailov et al. (2004) using observations on 6 high-latitude, 12 mid-latitude, and 8 low-latitude groundbased ionosonde stations located in the Eurasian longitudinal sector (Table 1).

Here, briefly repeat, for the sake of convenience, the main idea of Q-disturbances extraction from routine ionosonde observations. The $\left(N m \mathrm{~F} 2 / N m \mathrm{~F} 22_{\text {med }}-1\right) \times 100 \%$ hourly deviations exceeding $40 \%$ are considered as Q-disturbances if all 3-4 $A_{p}$ indices were $\leq 7$ for 24 preceding hours. The 27day $N m \mathrm{~F} 2$ running median, centered for the day in question rather than the usual monthly median, is used for the Q-disturbances extraction. Only long-duration $(\geq 3 \mathrm{~h})$ deviations were considered. The results for daytime (09:0015:00) LT conditions are given in Fig. 1 for negative (left panels) and positive (right panels) Q-disturbances. For a comparison and further discussion, similar seasonal variations are shown for the occurrence of usual storm-induced negative and positive F2-layer perturbations (Fig. 2). They were obtained by subtracting Q-disturbance from all F2-layer disturbance cases observed at each station.

Negative Q-disturbances are seen to cluster around winter solstice (November-January), however a summer (MayJune) peak in their occurrence is well pronounced at low latitudes (Fig. 1, left panels). Usual negative disturbances (Fig. 2, left panels), naturally, are much more numerous and they exhibit well-known semi-annual variations with the occurrence peaking around equinoxes. But at low latitudes, we have a well-pronounced summer peak in their occurrence. Therefore, two types of negative F2-layer disturbances demonstrate quite different occurrence frequency seasonal variations.

The occurrence for positive Q-disturbances mainly exhibits semi-annual variations at high and middle latitudes, but two peaks merge to one summer peak at low latitudes. At high latitudes the peaks occur in March and October, at middle latitudes they shift to April and September, and at low they merge to one May-June peak. It is interesting to note that although negative and positive Q-disturbances have different formation mechanisms (Mikhailov et al., 2007a, b), the occurrence peaks at low latitudes take place in the same months (May-June).

Usual storm-induced positive F2-layer disturbances at high latitudes mainly show semi-annual variations in the occurrence although the seasonal (winter/summer) component is also large. Note the similarity in the occurrence variations for usual negative and positive disturbances at high latitudes (Fig. 2, top panels). At middle latitudes usual positive disturbances mainly exhibit well-known seasonal variations with the winter occurrence being larger than the summer one. At low latitudes, seasonal variations are not pronounced (Fig. 2, bottom left panel), but small summer and winter peaks may be noted. As in the case of Q-disturbances usual positive and negative F2-layer storms exhibit different seasonal variations in their occurrence and this is related to different formation mechanisms.

\section{Interpretation}

In accordance with the present-day understanding of the ionosphere-thermosphere system (Duncan, 1969; Mayr and Volland, 1972; Prölss, 1995; Forbes et al., 1996; Field et al., 1998; Rishbeth, 1998; Rishbeth and Müller-Wodarg, 1999; Burns et al., 2004, and references therein) the solardriven and storm-induced (due to high-latitude heating) thermosphere circulations interaction is the basic process controlling the ionospheric F-region. This control is provided via neutral composition, temperature and plasma drifts produced mainly by thermospheric winds. Therefore, we should 

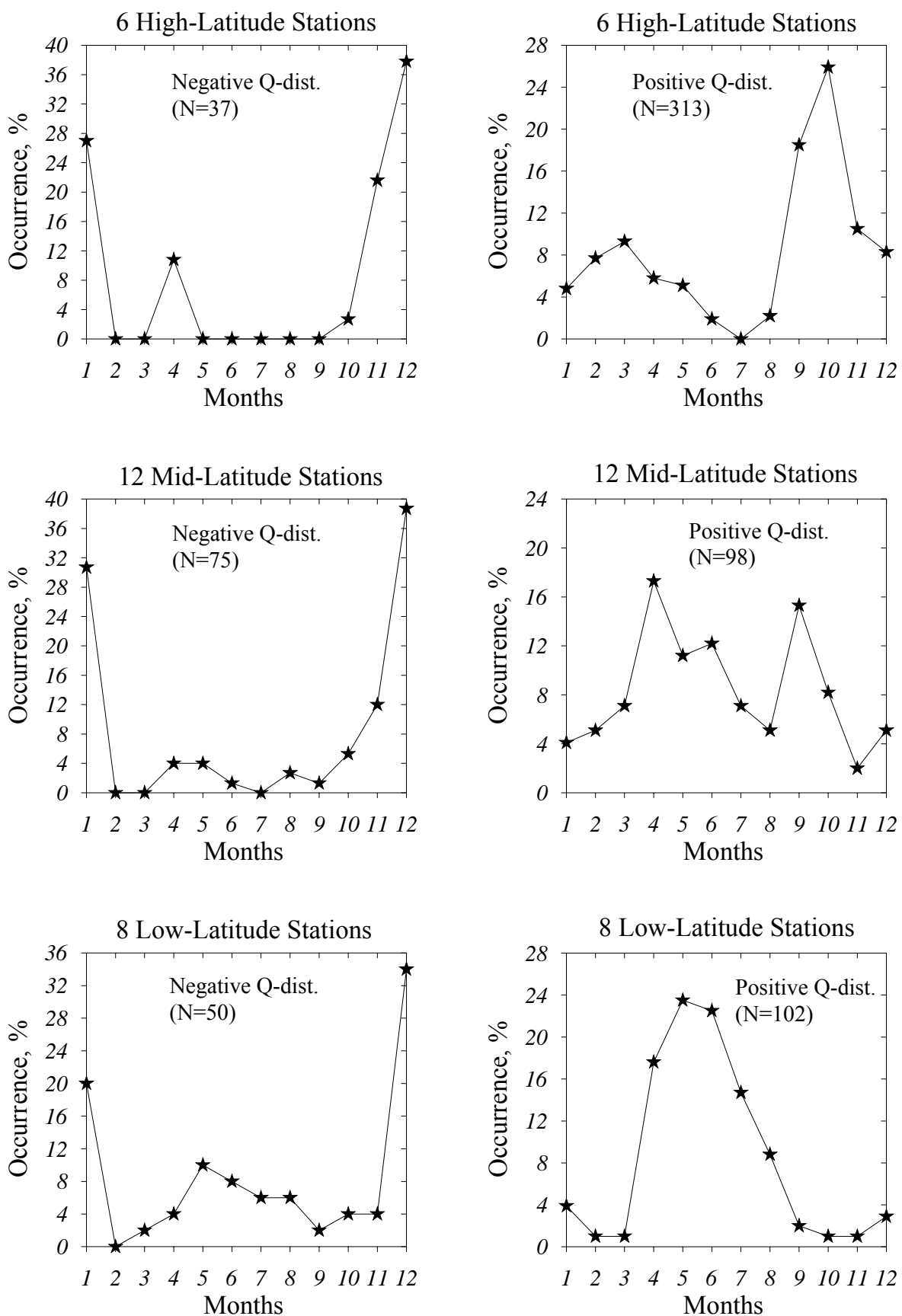

Fig. 1. Seasonal variations of the occurrence for negative (left panels) and positive (right panels) Q-disturbances at high, middle, and lower latitude stations in the daytime (09:00-15:00) LT sector. All solar activity levels are put together, total number of events is given in brackets.

consider seasonal variations of the solar driven (background) winds and the high-latitude heating source efficiency. According to radar observations (Duboin and Lafeuille, 1992; Buonsanto and Witasse, 1999; Kawamura et al., 2000) as well as to the HWM model (Hedin et al., 1996) the meridional daytime wind $V n x$ exhibits strong seasonal variations. Table 2 gives measured noon $V n x$ values for four seasons under solar maximum and minimum conditions and low ge- omagnetic activity. A pronounced winter-to-summer $V n x$ decrease is a well-known feature of the thermospheric circulation (Table 2).

The other parameter - high-latitude heating also exhibits seasonal variations, summer heating being stronger than winter one (Forbes et al., 1996; Rodger et al., 2001). The high-latitude heating changes the global distribution of pressure gradients suppressing, to some extent, the background 

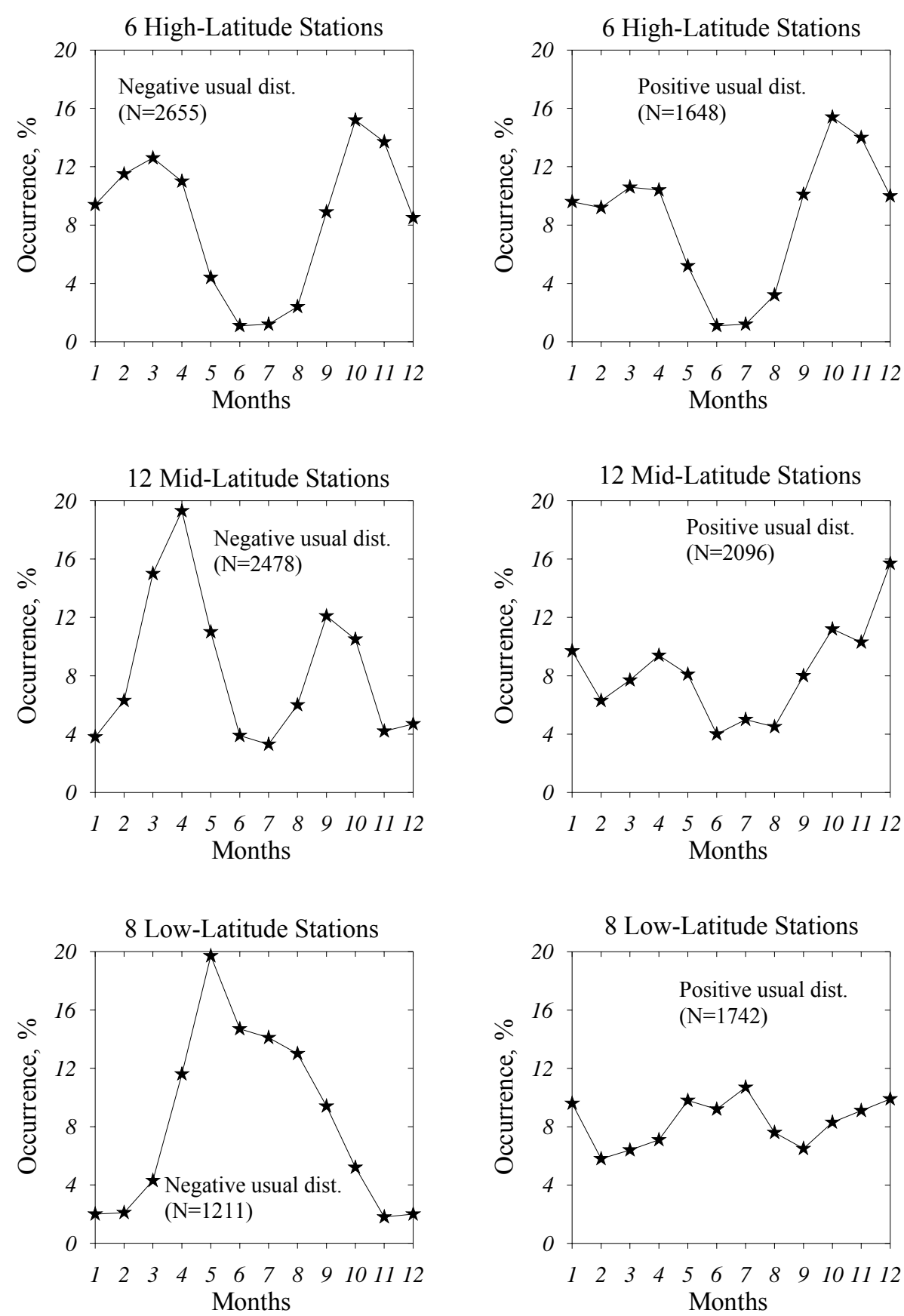

Fig. 2. Seasonal variations of the occurrence for usual storm-induced negative (left panels) and positive (right panels) F2-layer disturbances at high, middle, and lower latitude stations in the daytime (09:00-15:00) LT sector. All solar activity levels are put together, total number of events is given in brackets.

solar-driven $V n x$. Therefore, the zone of daytime downwelling (Rishbeth, 1998; Rishbeth and Müller-Wodarg, 1999; Richmond and Lu, 2000) should shift to lower latitudes as we pass from winter to summer. The downwelling is known to result in the atomic oxygen abundance increase. This effect is reflected in the NRLMSISE-00 empirical model (Picone et al., 2002). Model variations of the atomic oxygen concentration at $300 \mathrm{~km}$ are shown in Fig. 3 for February, March, and May. Although the calculated model variations of $[\mathrm{O}]$ are small, they clearly show the tendency for the peak in the atomic oxygen distribution to shift from relatively high $\left(\varphi \approx 50^{\circ}\right)$ latitudes in February to lower $\left(\varphi \approx 25^{\circ}\right)$ latitudes in May, supporting the idea of shifting the zone of downwelling to lower latitudes in summer. This may 
Table 2. Observed quiet time northward thermospheric wind velocity $(\mathrm{m} / \mathrm{s})$ at noon under solar maximum (first line) and solar minimum (second line) conditions.

\begin{tabular}{ccccl}
\hline Winter & Spring & Summer & Autumn & Reference \\
\hline 50 & 45 & 35 & 25 & Duboin and \\
75 & 50 & 35 & 45 & Lafeuille (1992) \\
45 & 30 & 0 & 50 & Buonsanto and \\
45 & 25 & -25 & 0 & Witasse (1999) \\
50 & 0 & 0 & 20 & Kawamura \\
80 & 60 & 0 & 30 & et al. (2000) \\
\hline
\end{tabular}

explain the shift of the vernal occurrence peak from March to May (Fig. 1, right panels) as the formation mechanism of positive Q-disturbances is related to the atomic oxygen abundance (Mikhailov et al., 2007a). After summer solstice, the process reverses: the poleward $V n x$ increases (Table 2), the single summer low-latitude occurrence peak splits and the autumnal peak shifts from September at mid-latitudes to October at high latitudes (Fig. 1, right panels).

Positive Q-disturbances appear under slightly enhanced auroral activity when the high-latitude heating increases and damps the solar-driven poleward thermospheric circulation (Mikhailov et al., 2007a). This damping produces a downwelling of the neutral gas with the corresponding enrichment of the thermosphere with atomic oxygen at F2-region heights. The damped poleward neutral wind also reduces the downward plasma drift in the F2-region, in this way increasing $N m \mathrm{~F} 2$. The tendency of the high- and middle-latitude positive Q-disturbances to cluster around equinoxes (Fig. 1, right panels) can be related, on the one hand, with the maximal occurrence of geomagnetic disturbances (of low intensity as well) during equinoctial periods (Roosen, 1966). On the other hand, this effect can be related to the equinoctial transition in atomic oxygen abundance (Shepherd et al., 1999; Shiokawa and Kiyama, 2000; Mikhailov and Schlegel, 2001). The most probable reason for such variations is a change in the global circulation pattern accompanied by vertical motions inferred from observations at E-region heights (e.g. Ward et al., 1997).

Positive Q-disturbances and usual F2-layer long-duration positive disturbances belong to the same class of events (Mikhailov et al., 2007a). Both are related to low or moderate auroral activity when the solar-driven thermospheric circulation is damped and the neutral gas downwelling increases the atomic oxygen concentration in the thermosphere. Considering the results on usual positive F2-layer disturbances (Fig. 2, right panels) it should be kept in mind that the latter were obtained by subtracting positive Q-disturbance cases from all observed positive perturbations. Therefore in Fig. 2, we have a mixture of two types of disturbances - long-duration

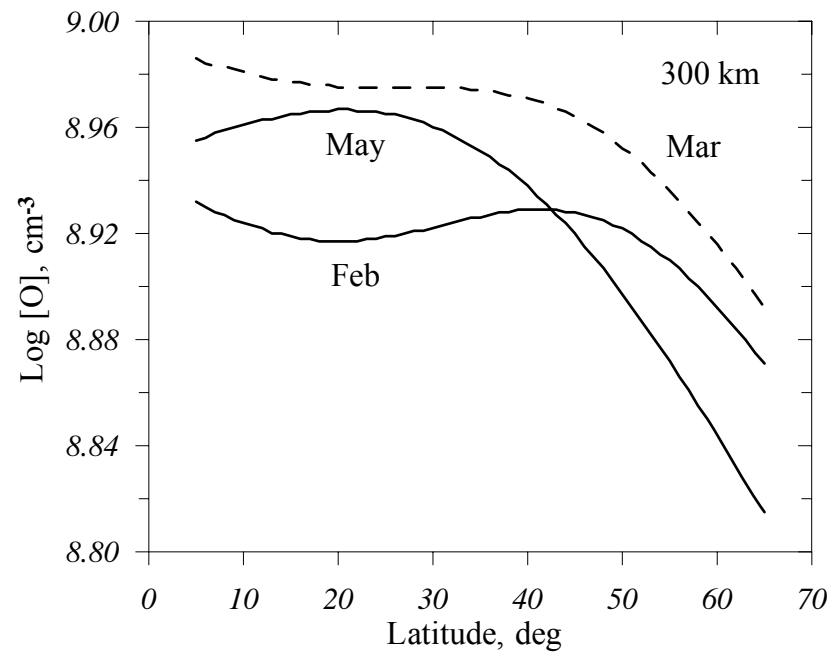

Fig. 3. The NRLMSISE-00 model latitudinal variations of atomic oxygen concentration under $\mathrm{F}_{10.7}=\mathrm{FS}_{10.7}=150$, and $A_{p}=7$ at $300 \mathrm{~km}$ height.

positive disturbances formed under moderate auroral activity and disturbances produced by elevated auroral activity. According to Zevakina and Kiseleva (1978), they present the positive disturbances of type I and type II, correspondingly. Unlike the first class, the disturbances of type II are usually observed during daytime (07:00-18:00 LT hours and they are followed by negative F2-layer storms. They are short in time, but their amplitude is larger compared to the type I. Disturbances of type II are accompanied by larger $h m \mathrm{~F} 2$ increase. They are produced by TADs and present the first phase of a two-phase (positive - negative) F2-layer disturbance.

This mixture of two types of disturbances is reflected in the occurrence frequency seasonal variations (Fig. 2, right panels). The semi-annual component may be attributed to long-duration disturbances of type I (cf. Fig. 1 with positive Q-disturbances, ) while the seasonal component may be attributed to the disturbances of type II produced by winds. On one hand, in winter the composition disturbance zone with a decreased $\mathrm{O} / \mathrm{N}_{2}$ ratio is restricted to the higher latitudes, thus mid-latitudes are mostly subjected to wind perturbations (Prölss, 1995). On the other hand, the winter thermosphere is cooler than the summer one and the same height shift $\Delta z$ of the F2-layer due to the wind corresponds to a larger change in $\mathrm{O} / \mathrm{N}_{2}$ ratio as $\Delta\left(\mathrm{O} / \mathrm{N}_{2}\right) \sim 0.75 / \mathrm{H} \exp (0.75 / \mathrm{H}) \Delta z$, where $\mathrm{H}=\mathrm{kT} / \mathrm{mg}$ is atomic oxygen scale height. Both factors result in higher occurrence of positive disturbances in winter. The contribution of the disturbances of type I is manifested in the summer peak of the occurrence at low latitudes (Fig. 2, right lower panel).

Negative Q-disturbances occur under so called ground state of the thermosphere which corresponds to very low geomagnetic activity with an unconstrained solar-driven thermospheric circulation characterized by relatively strong daytime 
poleward wind and relatively low atomic oxygen concentration at middle and sub-auroral latitudes (Mikhailov et al., 2007a). Both factors lead to a decrease in $N m F 2$. The clustering of the negative Q-disturbances around winter solstice (Fig. 1, left panels) is related to the poleward wind $V n x$ which is the strongest in winter (Table 2).

At lower latitudes there is a well-pronounced secondary (summer) peak in the occurrence of negative Q-disturbances (Fig. 1, left lower panel). Its formation may be related to the same earlier considered process of summer downwelling at lower latitudes. As it was shown earlier by Mikhailov et al. (2007a), the appearance of negative Q-disturbances does not imply any special physical process but just manifests the difference between the $N m \mathrm{~F} 2$ values corresponding to the ground state of the ionosphere and the current median level. The latter is always higher as it bears the effect of downwelling (increased $[\mathrm{O}]$ ) under low and moderate geomagnetic activity. Indeed, the analysis of summer low-latitude negative Q-disturbance cases has shown that for them the average $A_{p}=4.0 \pm 1.87$ while the average $A_{p}=10.0 \pm 5.1$ for the 27-day medians which were used to extract these Qdisturbances cases.

Usual negative storm-induced and Q-disturbances are due to different formation mechanisms and this results in different morphology (Mikhailov et al., 2004, 2007a, b) and in particular in different seasonal/latitudinal variations (Figs. 1 and 2, left panels). At high and middle latitudes, we have mainly semi-annual variations (Fig. 2) for the occurrence of usual negative F2-layer disturbances. They are due to semiannual variations of geomagnetic activity (Roosen, 1966) and the related decrease in the $\mathrm{O} / \mathrm{N}_{2}$ ratio (Prölss, 1980, 1995). But at lower latitudes, we have one summer peak in the occurrence frequency (Fig. 2, left bottom panel). This is due to the two previously mentioned wind systems interaction when in summer under weak northward $V n x$ the $[\mathrm{O}] /\left[\mathrm{N}_{2}\right]$ disturbance zone extends all the way from the polar to the low latitudes (Prölss and von Zahn, 1977).

\section{Discussion}

It was mentioned in the Introduction that F2-layer Qdisturbances is a weakly developed direction in the ionospheric physics. Therefore their morphology, formation mechanisms and the difference from usual F2-layer storm effects may have certain interest. Some aspects of this issue have been considered by Mikhailov et al. (2007b). It was stressed that negative F2-layer storms related to geomagnetic activity and Q-disturbances belong to different classes of events and exhibit different morphology with respect to: (a) $h m \mathrm{~F} 2$ variations; (b) $\mathrm{Ne}$ (h) distributions; (c) seasonal and latitudinal variations of the occurrence frequency. A quantitative analysis of daytime negative mid-latitude Q-disturbances has been done using Millstone Hill ISR observations which helped us understand the role of main aeronomic parame- ters in their formation. In this paper, we continue this analysis and an attempt has been made to explain the seasonal variations of the occurrence for positive and negative Qdisturbances at high, middle, and low latitudes and discuss the difference with usual storm-induced F2-layer perturbations.

The present-day concept of the thermosphere-ionosphere interaction, based on the two circulation systems (solardriven and storm-induced) interaction, has been applied to the analysis of the seasonal/latitudinal variations of the Qdisturbances occurrence and it turned out to be successful. This confirms, once more, the validity of the concept as the explanation of the Q-disturbances morphology may be considered as an absolutely independent check of this concept.

As the problem of Q-disturbances is a new one, it may make sense to specify once again the geophysical conditions when this type of F2-layer disturbances can be observed. Negative Q-disturbances occur under so called ground state of the thermosphere which corresponds to very low geomagnetic activity with an unconstrained solar-driven thermospheric circulation characterized by relatively strong daytime poleward wind and relatively low atomic oxygen concentrations at middle and sub-auroral latitudes (Mikhailov et al., (2007a). Actually, the occurrence of negative Q-disturbances is not related to any physical process, but depends on the $N m F 2$ median level they are counted from. If the month was geomagnetically disturbed with the usual negative F2layer storm events, the $\mathrm{Nm} \mathrm{F} 2$ median level is lower and this prevents the appearance of the negative Q-disturbances. On the contrary, the negative Q-disturbances should appear if a month was quiet and the $N m \mathrm{~F} 2$ median level was relatively high.

Positive Q-disturbances appear under slightly enhanced auroral activity when the high-latitude heating increases and damps the solar-driven poleward thermospheric circulation. This damping produces a downwelling of the neutral gas with the corresponding enrichment of the thermosphere with atomic oxygen at F2-region heights. Some quantitative estimates can be given to specify the term "slightly enhanced auroral activity". As it was pointed out by Mikhailov et al. (2007a), positive Q-disturbances just present the left-hand wing of the positive long-duration F2-layer disturbances area on the $A_{p}$-index scale. The mechanism of both disturbances is the same: the damped poleward circulation and neutral gas downwelling resulting in the $[\mathrm{O}]$ abundance increase. The F2-layer long-duration positive storm effect is, above all, a phenomenon taking place at a low geomagnetic activity $10<\sum k p<20, \mathrm{AE}_{\max }=200-400 \mathrm{nT}, D_{s t}=10-30 \mathrm{nT}($ Zevakina and Kiseleva, 1978), therefore positive Q-disturbances may appear even under $\mathrm{AE}<200 \mathrm{nT}$ and daily $A_{p}=3-4$.

The other question - why, under the same very low level of geomagnetic activity, do we have either negative or positive Q-disturbances? On one hand, it may be pertinent to note that according to Burke et al. (2007), significant energy can be deposited in the ionosphere without equal magnetic 
perturbations on the ground. Therefore, low level of geomagnetic activity measured in conventional magnetic indices, may not adequately present a real situation in the ionosphere. However, a more plausible mechanism may be related to the dayside cusp.

Here, we have the situation similar to slightly elevated auroral activity which was considered earlier. Heated thermosphere above the dayside cusp (Lühr et al., 2004; Schlegel et al., 2005; Demars and Schunk, 2007) changes pressure gradients and damps the solar-driven poleward wind stimulating neutral gas downwelling by this way at sub-auroral and middle latitudes. The latter, as it was shown by Rishbeth (1998, his Fig. 3), increases the atomic oxygen abundance in the thermosphere. The $\mathrm{O} / \mathrm{N}_{2}$ ratio increase, along with the downward plasma drift decrease (due to the poleward $V n x$ decrease), provide the $N m \mathrm{~F} 2$ increase during sunlit hours. Therefore, daytime positive Q-disturbances observed under very quiet geomagnetic conditions, may be related to the dayside cusp activity. An additional analysis is needed to specify the required geophysical conditions when the dayside cusp is efficient to produce such a type of F2-layer positive disturbances and when it does not "work" creating favorable conditions for negative Q-disturbances to occur.

Here, we have considered the simplest daytime conditions when the occurrence variations are well-pronounced and the theory of daytime F2-region formation is relatively simple and well-developed. Both negative and positive Qdisturbances are much more numerous in the evening and nighttime LT sectors (Mikhailov et al., 2004) and the seasonal variations for their occurrence look quite different. For instance, positive Q-disturbances exhibit a large occurrence peak in May at high and middle latitudes. Moreover, under a large number of positive nighttime events it was possible to divide them into different levels of solar activity (Mikhailov et al., 2004, their Fig. 6). The seasonal variations of the occurrence look quiet different for various solar activity levels. No reasonable explanation to these effects can be proposed at present and additional efforts are required to understand such seasonal variations.

Concerning the results on usual F2-layer disturbances, it is interesting to note the similarity in the seasonal variations of the occurrence for negative and positive storm events (Fig. 2, top panels). The number of events analyzed is large enough to consider this similarity as a real one. The only explanation is to suppose that the majority of positive disturbances considered belong to the type II (Zevakina and Kiseleva, 1978). In this case, both positive and negative disturbances belong to the same storm events (positive and negative phases) and, therefore, exhibit the same occurrence variations. It should be stressed that, for our analysis, we selected sub-auroral (high-latitude) stations with $\Phi_{\text {inv }} \leq 64^{\circ}$, i.e. located outside the plasma ring precipitation zone during daytime hours ( $\mathrm{Sa}$ galin and Smiddy, 1974). Therefore, the F2-layer positive effects should be attributed to vertical plasma drifts (increased equatorward $V n x)$ rather than particle precipitation.
Finally, some words concerning the origin of the analyzed seasonal/latitudinal variations of the Q-disturbances occurrence. The morphology of Q-disturbances (Mikhailov et al., 2004) differs essentially from the morphology of usual F2-layer storm effects related to geomagnetic activity and initially we were supposed to relate some morphological features with the observed variations in the lower thermosphere parameters. For instance, WINDII observations of zonal wind in the E-region (Shepherd et al., 1999, their Fig. 6a) has shown a well-pronounced upsurge in the eastward wind at $\varphi \approx 40 \mathrm{~N}$ maximizing exactly in May when we have the low-latitude (also around $\varphi \approx 40 \mathrm{~N}$ ) peak in the positive Q-disturbances occurrence frequency (Fig. 1, right bottom panel). Keeping in mind that the atomic oxygen [O] abundance is related to the low-thermosphere winds (Ward et al., 1997; Fauliot et al., 1997) and positive Qdisturbances are mainly due to [O] variations (Mikhailov et al., 2007a), there was a hope to relate these two features. However, further analysis has shown that the observed seasonal/latitudinal variations of the Q-disturbances occurrence may be explained by the thermospheric processes solely. The same turned out to be valid to interpret some other morphological features of Q-disturbances (Mikhailov et al., 2007a, b). It should be mentioned that Rishbeth (2006) has also expressed a restrained optimism with regard to the F-region lower atmosphere links.

\section{Conclusions}

The main results of our analysis can be summarized as follows:

1. Seasonal/latitudinal variations of the occurrence for daytime F2-layer positive and negative Q-disturbances can be explained in the framework of the presentday understanding of the thermosphere-ionosphere system. The basic process is the solar-driven and storminduced thermospheric circulations interaction, which varies with season and latitude. This concept allows us to explain both usual storm-induced and Q-disturbance seasonal/latitudinal variations of their occurrence although their morphology and formation mechanisms are different. This result may be considered as an obvious success of the concept.

2. Negative Q-disturbances occur under so called ground state of the thermosphere which corresponds to very low geomagnetic activity with an unconstrained solardriven thermospheric circulation characterized by relatively strong daytime poleward wind and relatively low atomic oxygen concentration at middle and sub-auroral latitudes (Mikhailov et al., 2007a). Both factors lead to a decrease in $N m \mathrm{~F} 2$. Therefore, the clustering of daytime negative Q-disturbances around winter solstice is 
related to the poleward wind $V n x$ which is the strongest in winter.

3. Positive Q-disturbances appear under slightly enhanced auroral activity when the high-latitude heating increases and damps, to some extent, the solar-driven poleward thermospheric circulation (Mikhailov et al., 2007a). This damping produces a downwelling of the neutral gas with the corresponding enrichment of the thermosphere with atomic oxygen at F2-region heights. The damped poleward neutral wind also reduces the downward plasma drift in the F2-region, in this way, increasing $N m \mathrm{~F} 2$. Therefore, the tendency of the highand middle-latitude positive Q-disturbances to cluster around equinoxes can be related, on the one hand, to the maximal occurrence of geomagnetic disturbances (of low intensity as well) during equinoctial periods. On the other hand, this effect can be related to the equinoctial transition in atomic oxygen abundance (Shepherd et al., 1999; Shiokawa and Kiyama, 2000; Mikhailov and Schlegel, 2001).

4. Seasonal changes in the poleward thermospheric wind and the auroral heating efficiency shift the zone of downwelling to lower latitudes in summer. This may explain the merging of the equinoctial peaks in the positive Q-disturbances occurrence to one summer peak at lower latitudes.

5. An interesting morphological result - the secondary occurrence peak for negative Q-disturbances at lower latitudes which is also observed in May-June as it takes place for positive Q-disturbances - may be related to the same summer downwelling at lower latitudes. The process of downwelling elevates the $\mathrm{NmF} 2$ median level which negative Q-disturbances are counted from.

Acknowledgements. This work was in part supported by the Russian Foundation for Basic Research under Grant 06-05-64227).

Topical Editor M. Pinnock thanks two anonymous referees for their help in evaluating this paper.

\section{References}

Altadill, D. and Apostolov, E. M.: Vertical propagating signatures of wave-type oscillations (2-and 6.5-days) in the ionosphere obtained from electron-density profiles, J. Atmos. Solar-Terr. Phys., 63, 823-834, 2001.

Apostolov, E. M., Altadill, D., and Alberca, L.: Characteristics of quasi-2-day oscillations in the foF 2 at northern middle latitudes, J. Geophys. Res., 100, 12 163-12 171, 1995.

Buonsanto, M. J. and Witasse, O. G.: An updated climatology of thermospheric neutral winds and $\mathrm{F}$ region ion drifts above Millstone Hill, J. Geophys. Res., 104, 24 675-24 687, 1999.

Burns, A. G., Killeen, T. L., Wang, W., and Roble, R. G.: The solarcycle-dependent response of the thermosphere to geomagnetic storms, J. Atmos. Solar-Terr. Phys., 66, 1-14, 2004.
Burke, W. J., Huang, C. Y., Marcos, F. A., and Wise, J. O.: Interplanetary control of thermospheric densities during large magnetic storms, J. Atmos. Solar-Terr. Phys., 69, 279-287, 2007.

Chen, P.-R.: Two-day oscillation of the equatorial ionization anomaly, J. Geophys. Res., 97, 6343-6357, 1992.

Danilov, A. D.: Meteorological control of the D-region, Ionospheric Res., Moscow, 39, 33-42, 1986 (in Russian).

Danilov, A. D., Kazimirovsky, E. S., Vergasova, G. V., and Khachikjan, G. Ya.: The meteorological effects in the ionosphere, Hydrometeoizdat, Leningrad, pp. 270, 1987 (in Russian).

Demars, H. G. and Schunk, R. W.: Thermospheric response to ion heating in the dayside cusp, J. Atmos. Solar-Terr. Phys., 69, 649660, 2007.

Depueva, A. H., Mikhailov, A. V., and Depuev, V. H.: Quiet time F2-layer disturbances at geomagnetic equator, Int. J. Geomag. Aeronom., 1-11, GI3001, doi:10.1029/2004GI000071, 2005.

Depuev, V. H., Depueva, A. H., and Leschinskaya, T. Yu.: Formation mechanism of Q-disturbances in the equatorial ionospheric F2-region, Geomag. Aeronom., 48, 93-102, 2008 (in Russian).

Duboin, M.-L. and Lafeuille, M.: Thermospheric Dynamics above Saint-Santin: Statistical study of the data set, J. Geophys. Res., 97(A6), 8661-8671, 1992.

Duncan, R. A.: F-region seasonal and magnetic-storm behavior, J. Atmos. Terr. Phys., 31, 59-70, 1969.

Fauliot, V., Thuillier, G., and Vial, F.: Mean vertical wind in the mesosphere-lower thermosphere region $(80-120 \mathrm{~km})$ deduced from the WINDII observations on board UARS, Ann. Geophys., 15, 1221-1231, 1997, http://www.ann-geophys.net/15/1221/1997/.

Field, P. R., Rishbeth, H., Moffett, R. J., Idenden, D. W., FullerRowell, T. J., Millward, G. H., and Aylward, A. D.: Modelling composition changes in F-layer storms, J. Atmos. Solar-Terr. Phys., 60, 523-543, 1998.

Forbes, J. M., Gonzalez, R., Marcos, F. A., Revelle, D., and Parish, H.: Magnetic storm response of lower thermosphere density, J. Geophys. Res., 101, 2313-2319, 1996.

Forbes, J. M. and Zhang, X.: Quasi 2-day oscillation of the ionosphere: a statistical study, J. Atmos. Solar-Terr. Phys., 59, 10251034, 1997.

Forbes, J. M., Palo, S. E., and Zhang, X.: Variability of the ionosphere, J. Atmos. Solar-Terr. Phys., 62, 685-693, 2000.

Hedin, A. E., Fleming, E. L., Manson, A. H., Schmidlin, F. J., Avery, S. K., Clark, R. R., Franke, S. J., Fraser, G. J., Tsuda, T., Vial, F., and Vincent, R. A.: Empirical wind model for the upper, middle and lower atmosphere, J. Atmos. Solar-Terr. Phys., 58, 1421-1447, 1996.

Hobara, Y. and Parrot, M.: Ionospheric perturbations linked to a very powerful seismic event, J. Atmos. Solar-Terr. Phys., 67, 677-685, 2005.

Kawamura, S., Otsuka, Y., Zhang, S.-R., and Fukao, S.: A climalogy of middle and upper atmosphere radar observations of thermospheric winds, J. Geophys. Res., 105, 12 777-12 788, 2000.

Kazimirovsky, E. S. and Kokourov, V. D.: The tropospheric and stratospheric effects in the ionosphere, J. Geomag. Geoelectr., 43 (Suppl), 551-562, 1991.

Kazimirovsky, E. S., Herraiz, M., and De la Morena, B. A.: Effects on the ionosphere due to phenomena occurring below it, Surv. Geophys., 24, 139-184, 2003.

Khachikjan, G. Ya.: Large scale meteorological disturbances and 
F2-layer. In: The meteorological effects in the ionosphere, Hydrometeoizdat, Leningrad, 210-245, 1987 (in Russian).

Laštovička, J., Križan, P., Šauli, P., and Novotná, D.: Persistence of the planetary wave type oscillations in foF 2 over Europe, Ann. Geophys., 21, 1543-1552, 2003, http://www.ann-geophys.net/21/1543/2003/.

Liu, J. Y., Chen, Y. I., Chuo, Y. J., and Chen, C. S.: A statistical investigation of preearthquake ionospheric anomaly, J. Geophys. Res., 111, A05304, doi:10.1029/2005JA011333, 2006.

Lühr, H., Rother, M., Köhler, W., Ritter, P., and Grünwaldt, L.: Thermospheric up-welling in the cusp region: evidence from CHAMP observations, Geophys. Res. Lett., 31, L06805, doi:10.1029/2003GL0119314, 2004.

Mayr, H. G. and Volland, H.: Magnetic storm effects in the neutral composition, Planet. Space Sci., 20, 379-393, 1972.

Mikhailov, A. V. and Schlegel, K.: Equinoctial transitions in the ionosphere and thermosphere, Ann. Geophys., 19, 783-796, 2001, http://www.ann-geophys.net/19/783/2001/.

Mikhailov, A. V., Depueva, A. H., and Leschinskaya, T. Yu.: Morphology of quiet time F2-layer disturbances: High and lower latitudes, Int. J. Geomag. Aeronom., 1-14, GI1006, doi:10.1029/2003GI000058, 2004.

Mikhailov, A. V., Depuev, V. H., and Depueva, A. H.: Synchronous $N m \mathrm{~F} 2$ and $N m \mathrm{E}$ daytime variations as a key to the mechanism of quiet-time F2-layer disturbances, Ann. Geophys., 25, 483-493, $2007 \mathrm{a}$ http://www.ann-geophys.net/25/483/2007/.

Mikhailov, A. V., Depueva, A. H., and Depuev, V. H.: Daytime F2-layer negative storm effect: what is the difference between storm-induced and Q-disturbance events?, Ann. Geophys., 25, 1531-1541, 2007b, http://www.ann-geophys.net/25/1531/2007/.

Picone, J. M., Hedin, A. E., Drob, D. P., and Aikin, A. C.: NRLMSISE-00 empirical model of the atmosphere: Statistical comparison and scientific issues, J. Geophys. Res., 107, 1468, 2002, doi:10.1029/2002JA009430.

Prölss, G. W.: Magnetic storm associated perturbations of the upper atmosphere: recent results obtained by satellite-borne gas analyzers, Rev. Geophys. Space Phys., 18, 183-202, 1980.

Prölss, G. W.: Ionospheric F-region storms, Handbook of Atmospheric Electrodynamics, vol. 2, edited by: Volland, H., CRC Press/Boca Raton, pp. 195-248, 1995.

Prölss, G. W. and von Zahn, U.: Seasonal variations in the latitudinal structure of atmospheric disturbances, J. Geophys. Res., 82, 5629-5632, 1977.

Richmond, A. D. and Lu, G.: Upper-atmospheric effects of magnetic storms: a brief tutorial, J. Atmos. Solar-Terr. Phys., 62, 1115-1127, 2000.
Rishbeth, H.: How the thermospheric circulation affects the ionospheric F2-layer, J. Atmos. Solar-Terr. Phys., 60, 1385-1402, 1998.

Rishbeth, H.: F-region links with the lower atmosphere?, J. Atmos. Solar-Terr. Phys., 68, 469-478, 2006.

Rishbeth, H. and Müller-Wodarg, I. C. F.: Vertical circulation and thermospheric composition: a modelling study, Ann. Geophys., 17, 794-805, 1999, http://www.ann-geophys.net/17/794/1999/.

Rishbeth, H. and Mendillo, M.: Patterns of F2-layer variability, J. Atmos. Solar-Terr. Phys., 63, 1661-1680, 2001.

Rodger, A. S., Wells, G. D., Moffett, R. J., and Bailey, G. J.: The variability of Joule heating, and its effects on the ionosphere and thermosphere, Ann. Geophys., 19, 773-781, 2001, http://www.ann-geophys.net/19/773/2001/.

Roosen, J.: The seasonal variation of geomagnetic disturbance amplitudes, Bull. Astr. Inst. Neth. 18, 295-305, 1966.

Sagalin, R. C. and Smiddy, M.: High latitude irregularities in the topside ionosphere based on ISIS-1 thermal ion probe data, J. Geophys. Res., 79, 4252-4260, 1974.

Schlegel, K., Lühr, H., St.-Maurice, J.-P., Crowley, G., and Hackert, C.: Thermospheric density stuctures over the polar regions observed with CHAMP, Ann. Geophys., 23, 1659-1672, 2005, http://www.ann-geophys.net/23/1659/2005/.

Sharma, D. K., Israil, M., Chand, R., Rai, J., Subrahmanyam, P., and Garg, S. C.: Signature of seismic activities in the F2 region ionospheric electron temperature, J. Atmos. Solar-Terr.Phys., 68, 691-696, 2006.

Shepherd, G. G., Stegman, J., Espy, P., McLandress, C., Thuillier, G., and Wiens, R. H.: Springtime transition in lower thermospheric atomic oxygen, J. Geophys. Res., 104, 213-223, 1999.

Shiokawa, K. and Kiyama, Y.: A search for the springtime transition of lower thermospheric atomic oxygen using long-term midlatitude airglow data, J. Atmos. Solar-Terr. Phys., 62, 1215-1219, 2000.

Vanina, L. B. and Danilov, A. D.: Relationship of the F2-region with the stratosphere parameters: only geomagnetically quiet days, Geomag i Aeronom., 45, 386-389, 2005 (in Russian).

Ward, W. E., Solheim, B. H., and Shepher, G. G.: Two day wave induced variations in the oxygen green line volume emission rate: WINDII observations, Geophys. Res. Lett., 24, 1227-1130, 1997.

Zevakina, R. A. and Kiseleva, M. V.: F2-region parameter variations during positive disturbances related to phenomena in the magnetosphere and interplanetary medium, in: The diagnostics and modelling of the ionospheric disturbances, Nauka, Moscow, 151-167, 1978 (in Russian). 